\title{
COMPARISON OF PERCUTANEOUS CYSTOLITHOLEPEXY WITH VESICOLITHOTOMY IN PEADIATRIC AGE GROUP FOR SAFETY AND EFFICACY.
}

1. MD, MS (Urology) Assistant Professor Urology Sheikh Zayed Hospital Rahim Yar Khan

2. MBBS, FCPS (Urology)

Assistant Professor Urology Sheikh Zayed Hospital Rahim Yar Khan.

3. MBBS

Medical Officer Urology

Sheikh Zayed Hospital Rahim Yar Khan.

4. MD, DMRD

Consultant Radiologist

Sheikh Zayed Hospital Rahim Yar Khan.

Correspondence Address:

Dr. Imran Hussain

Department of Urology

Sheikh Zayed Hospital Rahim Yar Khan

ih786pk@yahoo.com

Article received on: $11 / 09 / 2019$

Accepted for publication:

$30 / 12 / 2019$

\begin{abstract}
Imran Hussain ${ }^{1}$, Mohammed Farhan Qurashi' ${ }^{2}$, Shayan Rahim Kanjoo ${ }^{3}$, Asima Rashid ${ }^{4}$
\end{abstract}
ABSTRACT... Objectives: The purpose of study to evaluate post-operative outcome in terms of safety and accuracy of percutaneous cystolitholapaxy (PCVL) with open vesicolithotomy in children having Vesical stones. Study Design: Retrospective Comparative study. Setting: Department of Urology Sheikh Zayed Hospital Rahim Yar Khan. Period: January 2018 to December 2018. Material \& Methods: Data collected of 15 patient who underwent for open vesicolithotomy (group-I) and 15 children underwent for PCCL (group II) the patients' age ranged from 1 year to 10 years. The stone size ranged from $1 \mathrm{~cm}$ to $3 \mathrm{~cm}$ in both groups, the procedure was performed under anesthesia with intubation. Dilation of the tract was made with help of alken metallic dilators. We use the adult nephroscope with 24Fr sheath, the same which used for PCNL. Pneumatic fragmentation was required for stones larger than $1.5 \mathrm{~cm}$. Results: Procedures completed with complete stone clearance. The average hospital stay was 2.1 days in group I and 1.0 in group II. Analgesia requirement were 29.3 vs $12.3 \mathrm{mg}$. in group I, six patients $(40 \%)$ had fever while in group II only one patient $(6.7 \%)$ has fever. 5 patients observed with hematuria in group I while In group II it was observed in 2 patients. Conclusions: PCCL is a minimal invasive procedure with less morbidity in term of postoperative pain, urinary leakage, fever and hospital stay, and it is a cost effective option for small vesical stones.

Key words: Lithoclast, Nephroscope, Percutaneous Cysolitholepexy (PCCL), Vesicolithiasis, Vesicolithotomy.

Article Citation: Hussain I, Qureshi MF, Kanjoo SR, Rashid A. Comparison of percutaneous cystolitholepexy with vesicolithotomy in peadiatric age group for safety and efficacy. Professional Med J 2020; 27(8):1742-1746.

DOI: 10.29309/TPMJ/2020.27.08.4130

\section{INTRODUCTION}

Urolithiasis is the common disease of tropical and subtropical areas and in children, the urinary bladder is the most common site for stone formation in the lower urinary tract. ${ }^{1}$ Which account for $5 \%$ of urinary calculi. ${ }^{2}$ Incidence of vesicolithiasis decreased from few to none in the developed world while in many developing countries disease still exist notably in the, Africa, Middle East, South and East Asia which term as afro-Asian stone belt. ${ }^{2}$ Incidence is higher in boys as compare to girls with peak incidence at 5 year of age. ${ }^{3}$ Bladder calculi in children in the absence of infection, without any anatomical or neurological disease are considered to be endemic. ${ }^{4}$ Epidemiological data relate stone formation with nutrition which stated that early and frequent use of carbohydrate foods replacing milk feedings leads to a relative dietary deficiency of phosphates and the formation of insoluble urinary salts, ultimately leading to high ammonia excretion. These children also usually have a high intake of oxalate rich foods (increase oxalate crystalluria) and low animal proteins (low dietary citrate).$^{5}$ In girls, short urethral length facilitate to pass most of the calculus debris without retaining it in the bladder, but in most of males, stone nuclei are formed and retained. The growth of stones is determined by the effect of deposition and resorption mechanisms, which continue in progress with passage of time over many years till the patients present with symptoms and need surgical stone removal. ${ }^{3}$

Symptoms are lower abdominal pain, interruption of urinary stream, pulling and rubbing of penis. Sometime present with dysuria, frequency and poor stream or retention of urine. Traditionally 
vesicolithiasis usually treated by open vesicolithotomy, advancement in technology improve the management of vesicolithiasis from invasive to minimal invasive technique. Newer including transurethral stone fragmentation by intra-corporeal cystolithotripsy or by holmium laser, vesicolitholapaxy and percutaneous cystolithotripsy. All these innovative methods are less time consuming and cost effective regarding hospital stay and post-operative recovery time.

We planned and conducted above mentioned study to evaluate its success and safety of procedure in our department

\section{MATERIAL \& METHODS}

During January 2018 to December 2018, data of fifteen patients collected who underwent for open vesicolithotomy added in Group 1 and fifteen new patients selected for Group 2 who were planned for PCCL. Patient's age of upto10 years, stones upto $3 \mathrm{~cm}$ in size and those who were previously not operated, included in the study. Outcomes were observed in terms of analgesia requirement, fever, presence of hematuria, post-operative drain placement and hospital stay.

Written informed consent was taken with explanation of risks and benefits of the procedure to the patient and family. General anesthesia was administered with endotracheal intubation. Cystoscopy was done in all patients who underwent for PCCL in modified lithotomy position to push back the stone from urethra to urinary bladder and confirm the size and position of stone.

Adult nephroscope with 24Fr sheath was used for PCVL (Figure-1).

The standard open vesicolithotomy was performed in Group 1 in patients, while PCCL was performed in group 2 patients, after adequately filling urinary bladder with $8 \mathrm{fr}$ feeding tube, 18 gauge spinal needle inserted suprapubically, guide wire placed, serial dilatation done, amplatz sheath $28 \mathrm{Fr}$ placed, bladder examine with nephroscope, stone found and removed with help of triple jaws stone grasper (Figure-2), After completion the procedures, Foleys catheter for 03 days and nelton drain place for 24 hours in group 1 patients, while only suprapubic cystostomy tube was placed in group 2 patients.

For analgesia injection ketarolac $10 \mathrm{mg}$ was administered intra-venously. foleys catheter were removed after 03 days in group 1 and drain remove after 48 hours according to its requirement. In group 2 suprapubic cystostomy removed after 24 hours after observing the normal micturation per urethra. Group II were compared with group 1 in terms of post-operative discomfort, analgesia requirement, fever and hospital stay. Data was entered and processed using SPSS program. Numerical variables were described with mean \pm standard deviation and analyzed using student "t" test

Nominal variables were described in frequencies and percentages and analyzed by Chi Square. $P$ value of $<0.05$ was taken as significant.

\section{RESULTS}

Results are summarized in table-I and table-II, in group I mean age was 3.9 years and in group II 3.2 years. Twelve patients were male and 3 female in group I and 13 male and 2 female in group II. mean stone size was $2.9 \mathrm{~cm}$ in group I and in group II it was $1.8 \mathrm{~cm}$ In group I, six patients had fever and in group II, no patients had fever $(p<0.05)$. Analgesia requirement ranged from $10 \mathrm{mg}-40 \mathrm{mg}$ ketorolac mean requirement was $29.3 \mathrm{mg}$ in group I while In group II, analgesia requirement was from $10 \mathrm{mg}-20 \mathrm{mg}$ with a mean dose of $12.3 \mathrm{mg}(p<0.05)$.

In group I, hospital stay was between 1 to 3 days mean was 2.1 days. In group II, it was 1 day $(p<0.05)$.

In group I, hematuria was observed in 5 patients. In group II it was observed in 2 patients, $(p<0.05)$.

All patients in group 1 were catheterized for 5 days and drain were remove after 24to 48 hours before discharge while in group 2 suprapubic tube was clamped and removed after observing normal micturition within 24 hours. 

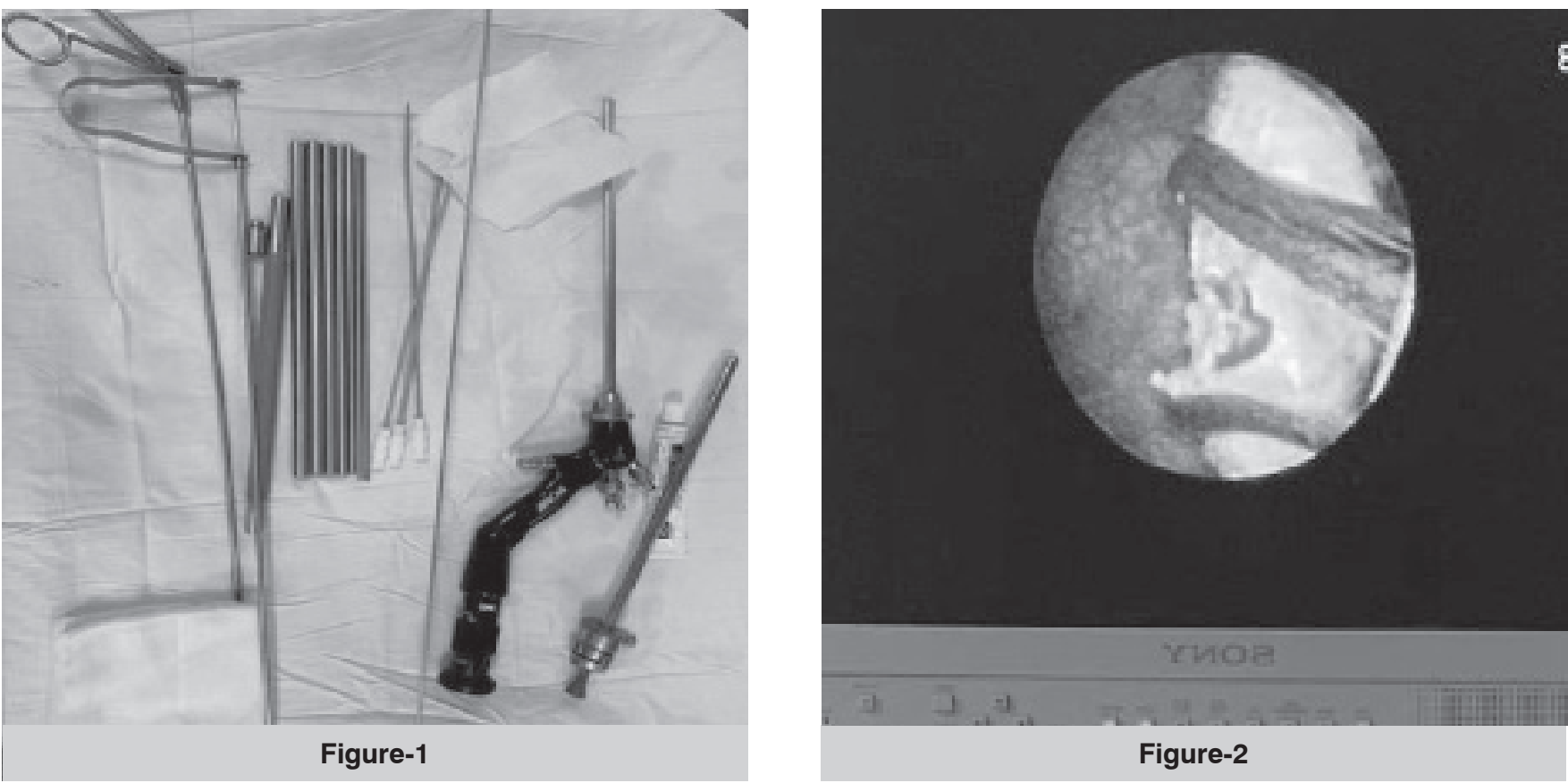

Figure-1

Figure-2

\begin{tabular}{|l|c|c|c|c|c|}
\hline \multirow{2}{*}{ Parameters } & \multicolumn{2}{|c|}{ Vesicolithotmy } & \multicolumn{2}{c|}{ PCVL } & P-Value \\
\hline Fever & $\mathbf{n}$ & \%age & $\mathbf{n}$ & \%age \\
\hline hematuria & 06 & $40 \%$ & 01 & $0.7 \%$ & $13.3 \%$ \\
\hline
\end{tabular}

\begin{tabular}{|c|c|c|c|c|c|c|}
\hline $\begin{array}{l}\text { Study parameters } \\
\text { (group } 1 \text { vs group2) }\end{array}$ & $\mathbf{N}$ & Mean & $\begin{array}{c}\text { Mean } \\
\text { Difference }\end{array}$ & SD & $\begin{array}{l}\text { Standard } \\
\text { Error }\end{array}$ & P-Value \\
\hline Age & \multirow{3}{*}{15 vs 15} & 3.9 vs 3.2 & 0.7 & 2.3 vs 1.3 & 0.599 vs 0.341 & ------ \\
\hline Analgesia & & 29.3 vs12.3 & 17 & 6.7 vs 3.7 & 1.75 vs0.959 & $<0.05$ \\
\hline Hospital Stay & & $2.1 \mathrm{vs} 1.0$ & 1.1 & 0.51 vs 0.0 & 0.133 vs 0.0 & $<0.05$ \\
\hline
\end{tabular}

\section{DISCUSSION}

Most common site for stone formation in the lower urinary tract is the urinary bladder the incidence of vesicolithiasis in children is slowly declining in endemic areas. This is mostly due to improved nutrition, improve living standards, access to better health care facilities for pre-natal care and improved awareness of the problem in the endemic areas. ${ }^{5}$

The techniques for vesical stones removal has been steadily refined and improved from standard vesicolithotomy to transurethral laser fragmentation and dusting of stones, aim of improvement in technique was reduce morbidity, open vesicolithotomy has a drawback of prolong hospital stay, increase analgesia dose requirement, possibility of wound infection, and catheter related complication due to prolong catheterization such as urinary tract infection and stricture formation in urethra etc. ${ }^{6}$

Transurethral disintegration and fragmentation of stones with pneumatic intra corporal lithotripsy are another minimally invasive procedure but have a problem with large stone fragments, prolong operative time and urethral manipulation even with small caliber instruments. 
In study of Isen et al in children with bladder stones by using transurethral pneumatic lithotripsy, in study it is observed that $7.4 \%$ of the patients required a second procedure to clear the fragments and relieve acute retention. The mean hospital stay was significantly higher. ${ }^{7}$

Problem of large fragments of stones can be resolved with use of laser or combine pneumatic and ultrasonic lithoclast but these devices are expensive and maintenance cost is a big challenge for small centers like ours. another study conducted in SIUT by Khossa, which show Ten (10\%) patients developed minor complications Five $(5 \%)$ patients developed immediate postoperative haematuria which was settled within a couple of hours, Four (4\%) patients developed difficulty in passing urine after the removal of the catheter which settled by itself on the first follow-up in a week. One (1\%) patient developed retention of urine which cause catheterization for 24 hours they observe 100\% stone-free rate after one session of cystolithoclast with minimal hospital stay from 10 to 12 hours. $^{8}$

PCCL is an effective treatment for vesicolithiasis, the procedure is not only easy to learn but also much easy to begin those centers where lower tract endourology are routinely performing even in $\mathrm{DHQ}$ levels, different techniques used for tract formation and stone retrieval, Nazeer, Rafiq Ahmad Sahito and Sharif et al used trochar and cannula to enter the bladder instead of serial dilatation of tract, they remove stone with stone punch. ${ }^{9}$

Akmal M, Munir Ml, used percutaneous technique under ultrasound guidance and serial dilatation by dilators for tract formation and then Amplantz sheath placed. Nephroscope used for stone retrieval while fragmentation of stone done with pneumatic lithoclast. ${ }^{10}$

In our study we used same tract dilatation technique with serial dialators and amplatz sheath applied for fragmentation of stone we used kinetic lithoclast as well as stone punch if we got difficulty in fragmenting stone due to its hardness. Result were quite favorable.

\section{CONCLUSION}

Based on our experience, we can conclude that PCCL is a safe and effective method for treatment of endemic bladder stones in children. It reduces morbidity and hospital stay, and thus the cost of treatment and can be easily initiated in those center where lower tract endo-urology already practicing.

Copyright $\odot 30$ Dec, 2019.

\section{REFRENCES}

1. Soliman NA, Rizvi SAH. Endemic bladder calculi in children. Pediatr Nephrol. 2017 Sep; 32(9):1489-1499.

2. Papatsoris AG, Varkarakis I, Dellis A, Deliveliotis C. Bladder lithiasis: From open surgery to lithotripsy. Urol Res 2006; 34(3):163-7.

3. Halstead SB. Epidemiology of bladder stone of children: Precipitating events. Urolithiasis. 2016 Apr; 44(2):101-8.

4. Degnari RA, Jalbani MH, Abro MA. Transurethral cystolithotripsy for bladder calculi in children. Med Channel 2009; 5(4):110-113.

5. Bhamar Lal, Jai Pal Paryani. Childhood bladder stones-an endemic disease of developing countries, J Ayub med Coll Abbottabad 2015; 27(1):17-21.

6. Hassan Ahmedania, Mehdi younesi Rostami. Percutaneous treatment of bladder calculi in children: 5 years' experience. Urology journal 2006; 3(1):20-22.

7. Isen K, Em S, Kilic V, Utku V, Bogatekin S, Ergin H: Management of bladder stones with pneumatic lithotripsy using a ureteroscope in children. J Endourol 2008; 22: 1037-40.

8. Ali Sher Khosa, Muhammad Hussain, Manzoor Hussain. Safety and efficacy of transurethral pneumatic lithotripsy for bladder calculi in children. J Pak Med Assoc2012; 62(12)1297-300.

9. Nazar AM. Percutaneous use of stone punch in the management of vesical calculi in children: A new treatment modality. Gomal J Med Sci 2006; 4:28-31.

10. Muhammad Akmal, Muhammad Irfan Munir. Percutaneous Cyst lithotripsy; Is it Safe and Successful in all age groups. APMC; 2017: 11(1):2527. 


\section{AUTHORSHIP AND CONTRIBUTION DECLARATION}

\begin{tabular}{|c|l|l|}
\hline Sr. \# & \multicolumn{1}{|c|}{ Author(s) Full Name } & \multicolumn{1}{|c|}{ Contribution to the paper } \\
\hline 1 & Imran Hussain & Author/Data analysis. \\
2 & M. Farhan Qurashi & Co-author/Proof reading. \\
3 & Shayan Rahim Kanjoo & Drafting/Data collection. \\
4 & Asima Rashid & $\begin{array}{l}\text { Diagnostic workup/Data } \\
\text { collection. }\end{array}$ \\
\hline
\end{tabular}

